\title{
Eating behaviour and its association with social living conditions and weight status among adolescent girls: results of the cross-sectional Berlin School Children's Cohort study
}

\author{
Anne-Madeleine Bau ${ }^{1, *}$, Sarah Krull ${ }^{2}$, Andrea Ernert ${ }^{3}$ and Birgit Babitsch ${ }^{2}$ \\ ${ }^{1}$ Institute for Experimental Pediatric Endocrinology, Charité - Universitätsmedizin Berlin, Augustenburger Platz 1, \\ 13353 Berlin, Germany: ${ }^{2}$ Master Program, Health \& Society: Gender and Diversity Studies, Berlin School of \\ Public Health, Berlin, Germany: ${ }^{3}$ Institute for Biostatistics and Clinical Epidemiology, Charité - Universitätsmedizin \\ Berlin, Berlin, Germany
}

Submitted 18 November 2010: Accepted 5 February 2011: First published online 5 April 2011

\begin{abstract}
Objective: To capture a more holistic picture of eating behaviour by investigating the impact of the social living conditions and weight status of parents and daughters on food consumption frequency, the context of meals and daily portion sizes.

Design: Cross-sectional Berlin School Children's Cohort study.

Setting: A total of sixty-nine schools in Berlin (3400000 inhabitants, eastern Germany) participated in the present study.

Subjects: A total of 1519 girls aged 11-14 years were selected. Bi- and multivariate analyses were performed to examine the impact of age, migration background, socio-economic status (SES), parental education, family situation and the weight status of parents and daughters on three different eating behaviour scores according to nutritional recommendations.

Results: For the three dependent eating behaviour variables, different patterns of influencing factors emerged. Multivariate regression (model 1) revealed that low and middle SES, two-parent migration background and older age were significant risk factors. Meal context was also significantly influenced by living with a single parent. Similar results were obtained for the daily portion size scores and maternal overweight status was the most influential. Model 2 succeeded in showing that, within the composite variable of family SES, mothers' level of education was the dominant component.

Conclusions: SES as a whole, and especially the component of mothers' level of education and two-parent migration background, was the strongest risk factor for an unfavourable eating pattern among adolescent girls. The results clearly indicated preventive potential. Using three different measures of eating behaviour simultaneously provided an in-depth understanding of general patterns and potential risk factors.
\end{abstract}

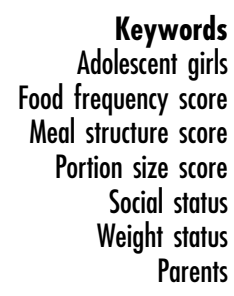

Keywords ood frequency score eal structure score Social status leight status Parents
The majority of Western citizens in the 21st century have all the prerequisites for leading a healthy life. However, non-communicable diseases partially caused by unhealthy eating behaviour are on the rise in industrialized nations $^{(1)}$. Research on eating behaviour tends to focus on eating disorders and obesity. Much research exists on the genetics of obesity, but little on the environment and intermediary behaviours (e.g. eating behaviour) that promote childhood overweight ${ }^{(2)}$. Unhealthy eating behaviour is labelled as a modifiable risk factor ${ }^{(1,3)}$ for non-communicable diseases and research on eating behaviour is crucial. Because of the vast number of variables, eating behaviour is one of the most complex behaviours and thus hard to capture ${ }^{(4)}$. Nevertheless, much literature exists on the effect of consumption frequency, such as breakfast habits, in adults or of specific food items, such as fruit, vegetables and sweets, in adolescents' eating behaviour $^{(5-7)}$. Research on eating behaviour in subpopulations and its influencing factors is also limited. Only a few studies exist on the eating behaviour of adolescent girls, especially those stratified by specific determinants such as socio-economic status (SES) and biological background. A report of the pan-European Health Behaviour in School-aged Children (HBSC) study acknowledges that 'research on SES differences in adolescent food habits is limited ${ }^{(5)}$. Recent results can be 
found in the German part of the HBSC study ${ }^{(8)}$, the German Health Interview and Examination Survey for Children and Adolescents (KiGGS) including the EsKiMo module (Nutrition Study as a KiGGS module) $)^{(4,9,10)}$, the DOrtmund Nutritional and Anthropometric Longitudinally Designed Study (DONALD) ${ }^{(11)}$ and, to a limited extent, in the Kiel Obesity Prevention Study (KOPS) ${ }^{(12)}$. The studies partially stratify for factors such as age, SES and weight status. During adolescence, girls may be especially susceptible to acquiring unhealthy eating habits and to disregarding nutritional recommendations ${ }^{(3,13)}$. Further, despite increased research interest in eating behaviour in children and adolescents, very few studies compare the determinants of different components of eating behaviour such as food frequency, meal context and portion size. All are crucial in the discussion of eating behaviour.

Against this background, the results of the present study add to the understanding of the impact of social factors (SES, parental education, family situation and weight status of parents and daughters) and weight status on eating behaviour. For the first time, different measures of eating behaviour are used to provide a comprehensive picture of this lifestyle component. The following hypotheses will be tested in bi- and multivariate analyses: the risk of unfavourable eating behaviour is increased with higher age, migration background, lower SES/ education, living with one parent, being overweight or obese and/or having overweight parents.

\section{Method}

\section{Design}

The data set of the Berlin School Children's Cohort (BSCOC) of the Institute for Experimental Paediatric Endocrinology at the Charité Virchow Hospital in Berlin, Germany, was used. A cross-sectional BSCOC study was conducted between September 2006 and March $2007^{(14)}$. The survey group was randomly selected from primary and secondary schools. Of 160 schools approached, sixty-nine participated in the study. A total of 1840 (40.8\% response) girls within the age range of 9-15 years and of grades 5-8 were enrolled, of whom 11-14-year-olds ( $n$ 1519) were selected for the secondary analysis ${ }^{(15)}$. After being intensively pre-tested in the target group, a standardized questionnaire consisting of eighty questions was given to the girls, including a thirteen-item standardized questionnaire for the parents. During the assessment period in the classroom, three study assistants supported the completion of the questionnaire. Information about nutrition, eating behaviour, migration background (country of birth, language and ethnicity) and family situation was collected. The parental questionnaire asked about migration, social background, parents' weight and height and was completed by $91.3 \%$ of the girls' parents. The present study was approved by the Charité Ethics Committee.

\section{Eating behaviour}

A comprehensive view was made possible for the first time by the use of three dependent variables of eating behaviour that provided information on the food items, portions and meal context. The 'food frequency score' was computed on the basis of data obtained through an FFQ enquiring into the frequency with which the respondents consumed twenty-eight food items (daily, multiple times per week, approximately once per week and less or never). The FFQ is adapted from the KOPS FFQ (twenty-six items) ${ }^{(16)}$, which was validated against a $7 \mathrm{~d}$ dietary record in twenty-four children. The individual frequencies were coded as $0=$ unfavourable, $1=$ normal and $2=$ optimal, according to the optimiX ${ }^{\circledR}$ recommendations of the Research Institute of Child Nutrition (Dortmund, Germany) ${ }^{(17,18)}$ and the dietary index according to Winkler et $a l^{(19)}$. The score is the sum of the individual frequencies; the higher the score the better the girls' eating behaviour. The maximal point value is 56 . Scores $\geq 75$ th percentile (35-56 points) are deemed optimal, scores $\geq 25$ th percentile but $<75$ th percentile (27-34 points) are deemed normal and those $<25$ th percentile ( $0-26$ points) are considered unfavourable.

The second variable 'meal context score' refers to eight questions on where and with whom the girls usually consume their meals. The location of breakfast, lunch and dinner was categorized as follows: at home, on the road, in school, usually skipped and I do not know. Company during mealtime was categorized as: with family or relatives, alone, with classmates and others. The snack behaviour variable counted the frequency of snacking between meals per day ( $\leq 1,2,3,>3$ times/d and I do not know). The variable 'eating in front of the television' had the following response options: never, sometimes, often and I do not know. The aforementioned eight categories were used to create the aggregated meal variable, using the concept of Winkler's three-category index: optimal (2), normal (1) and unfavourable ( 0 ; see Table 1 ). The points were added, with the highest score attainable being 16 and the lowest 3. Scores $\geq 75$ th percentile (15-16 points) were coded as optimal; those $\geq 25$ th percentile but $<75$ th percentile ( $12-14$ points) were coded as normal; and those $<25$ th percentile $(0-11$ points) were coded as unfavourable.

The third variable 'daily portion size' score consisted of fifteen food groups and the portions were measured according to the AID 'handmodell' (20). The portions on the questionnaire were categorized as follows: not at all; 1 times one handful $=$ one portion; 2 times one handful $=$ two portions; $3-4$ times one handful $=$ three to four portions; and $>4$ times one handful $=$ more than four portions. The responses to the beverage questions were categorized similarly, except that the word glass replaced the word handful. The students had to estimate their hand portions according to the size of their hand. The portion size score was coded according to the same pattern, whereby eating, for example, three to four portions of 
Table 1 Construction of meal score on the basis of recommendations according to optimiX ${ }^{\circledR(17,18)}$ and Winkler et al. ${ }^{(19)}$

\begin{tabular}{|c|c|c|c|c|c|}
\hline \multirow[b]{2}{*}{ Meals } & \multicolumn{5}{|c|}{ Location } \\
\hline & At home & On the road & In school & Usually skipped & I do not know \\
\hline Breakfast & 2 & 1 & 1 & 0 & 0 \\
\hline Lunch & 2 & 0 & 2 & 0 & 0 \\
\hline \multirow[t]{3}{*}{ Dinner } & 2 & 0 & 1 & 0 & 0 \\
\hline & \multicolumn{4}{|c|}{ With whom } & \\
\hline & Family, relatives & Alone & With classmates & Others & \\
\hline Breakfast & 2 & 1 & 1 & 1 & \\
\hline Lunch & 2 & 1 & 2 & 1 & \\
\hline Dinner & 2 & 1 & 1 & 1 & \\
\hline \multirow[t]{2}{*}{ Snacks } & $\leq 1$ time/d & 2 times/d & 3 times/d & $>3$ times $/ \mathrm{d}$ & I do not know \\
\hline & 2 & 1 & 0 & 0 & 0 \\
\hline \multirow[t]{2}{*}{ Eat in front of the television/computer } & Never & Sometimes & Often & I do not know & \\
\hline & 1 & 2 & 0 & 0 & \\
\hline
\end{tabular}

bread or rolls was coded as optimal (2 points), two portions were coded as normal (1 point) and eating fewer portions, as well as more than four portions, was coded as unfavourable (no point); higher scores indicate better food portion patterns. The possible cumulative points range from 0 to 30 . Students with scores $\geq 75$ th percentile (20-30 points) are categorized as having optimal portion scores. Scores $\geq 25$ th percentile but $<75$ th percentile (15-19 points) are deemed normal. Scores $<25$ th percentile (0-14 points) are assigned an unfavourable portion pattern.

The independent influencing factors were coded as follows. 'Age' was divided into four groups: 11-, 12-, 13and 14-year-olds. 'Highest level of education' attained by parents was measured individually and integrated into the SES index. 'SES' was calculated using the definition of the Administration for Health, Environment and Consumer Protection of the Berlin Senate ${ }^{(21)}$. In this index, parental education was weighted twice to emphasize its importance and employment status was counted once. 'Migration background' was defined as suggested by Schenk et al. ${ }^{(22)}$ : no, one-parent or two-parent migration background. If no information was available from parents but girls were born in Germany and had German nationality, the language spoken at home was chosen to categorize the migration background. 'Family situation' was coded as living with two adults or one parent. 'Height and weight of the parents' were self-reported. BMI was calculated as weight in kilograms divided by the square of height in metres $\left(\mathrm{kg} / \mathrm{m}^{2}\right)$. The categorical BMI variable was categorized as underweight $\left(\mathrm{BMI}<18 \cdot 0 \mathrm{~kg} / \mathrm{m}^{2}\right)$, normal $\left(\mathrm{BMI}=18 \cdot 0-24 \cdot 9 \mathrm{~kg} / \mathrm{m}^{2}\right)$ and overweight or obese $\left(\mathrm{BMI}>24.9 \mathrm{~kg} / \mathrm{m}^{2}\right.$ ) according to the WHO BMI classification ${ }^{(23)}$. The 'weight status of the girls' was categorized using the German reference definition $^{(24)}:<10$ th percentile was considered underweight and $>90$ th percentile was considered overweight. One study nurse measured the girls' body weight and height.
The Kruskall-Wallis test was performed to examine differences in food frequency consumption, meal context and daily portion sizes according to age group, migration background, SES, parental education, family situation and weight status of parents and daughters (Table 1). To analyse the risk of unfavourable patterns with regard to food frequency consumption, meal context and daily portion sizes, we used multivariate logistic regression models. The reference categories in all analyses were optimal or normal patterns. As predictors, the following variables were included in the logistic regression models: age (continuous), SES, migration background, parental education, family situation and weight status of parents and girls. For all three dependent variables, two models were calculated on the basis of the measure of social status. 'Model 1' included SES; 'model 2' comprised mothers' and fathers' education as two separate variables. OR, 95\% CI and statistical significance are documented in Tables 2 and 3. For all statistical tests, a level of significance of $5 \%$ was stated. All data analyses were performed using the Statistical Package for the Social Sciences statistical software package version $17 \cdot 0$ (SPSS Inc., Chicago, IL, USA).

\section{Results}

\section{Study population}

The distribution of the 1519 school girls stratified by age, migration background, SES, parental education, family situation and weight status of mother, father and daughter is shown in Table 2 . The age groups were unequally distributed with more girls in older age groups. In all, $64 \cdot 1 \%$ of the girls had no migration background ( $9 \cdot 1 \%$ one-parent; $26 \cdot 8 \%$ two-parent migration background). SES was distributed as follows: $25 \cdot 2 \%$ low, $36 \cdot 5 \%$ middle and $38.3 \%$ high SES, similarly in all age groups (not shown). Some $18 \cdot 3 \%$ of both parents had less than tenth grade 
Table 2 Frequency distribution of selected social and biological indicators (median, 25th and 75th percentiles) and association between eating behaviour and selected social and biological indicators among adolescent girls in Berlin

\begin{tabular}{|c|c|c|c|c|c|c|c|c|c|c|c|c|c|c|}
\hline & \multicolumn{2}{|c|}{ Total } & \multicolumn{4}{|c|}{ Food frequency score } & \multicolumn{4}{|c|}{ Meal context score } & \multicolumn{4}{|c|}{ Portion size score } \\
\hline & $n$ & $\%$ & 25th & Median & 75th & $P$ & 25th & Median & 75th & $P$ & 25th & Median & 75th & $P$ \\
\hline \multicolumn{15}{|l|}{ Age (years; $n$ 1519) } \\
\hline 11 & 146 & $9 \cdot 6$ & 28 & 32 & 36 & 0.007 & 15 & 17 & 20 & $<0.001$ & 13 & 14 & 15 & 0.653 \\
\hline 12 & 330 & $21 \cdot 7$ & 28 & 32 & 35 & & 15 & 18 & 20 & & 13 & 14 & 15 & \\
\hline 13 & 593 & $39 \cdot 0$ & 27 & 31 & 34 & & 14 & 17 & 20 & & 12 & 13 & 15 & \\
\hline 14 & 450 & $29 \cdot 6$ & 27 & 31 & 35 & & 14 & 17 & 20 & & 11 & 13 & 14 & \\
\hline \multicolumn{15}{|l|}{ Migration background ( $n$ 1413) } \\
\hline No & 906 & $64 \cdot 1$ & 28 & 32 & 36 & $<0.001$ & 12 & 14 & 15 & $<0.001$ & 15 & 18 & 20 & $<0.001$ \\
\hline One parent & 128 & $9 \cdot 1$ & 29 & 33 & 36 & & 12 & 14 & 15 & & 16 & 18 & 21 & \\
\hline Two parents & 379 & $26 \cdot 8$ & 25 & 29 & 33 & & 11 & 13 & 14 & & 13 & 16 & 19 & \\
\hline \multicolumn{15}{|l|}{ SES parents $(n 1341)$} \\
\hline Low & 338 & $25 \cdot 2$ & 25 & 28 & 32 & $<0.001$ & 11 & 13 & 14 & $<0.001$ & 14 & 16 & 18 & $<0.001$ \\
\hline Middle & 490 & $36 \cdot 5$ & 28 & 31 & 35 & & 12 & 13 & 15 & & 15 & 17 & 20 & \\
\hline High & 513 & $38 \cdot 3$ & 30 & 33 & 37 & & 13 & 14 & 15 & & 16 & 19 & 21 & \\
\hline \multicolumn{15}{|l|}{ Mother's education ( $n$ 1344) } \\
\hline Less than 10th grade & 246 & $18 \cdot 3$ & 25 & 28 & 33 & $<0.001$ & 11 & 13 & 14 & $<0.001$ & 13 & 16 & 18 & $<0.001$ \\
\hline 10th grade & 497 & $37 \cdot 0$ & 27 & 31 & 34 & & 12 & 13 & 14 & & 14 & 17 & 19 & \\
\hline $\begin{array}{l}\text { 13th grade (Arbitur) and higher } \\
\text { (university) }\end{array}$ & 601 & $44 \cdot 7$ & 29 & 33 & 36 & & 12 & 14 & 15 & & 16 & 19 & 21 & \\
\hline \multicolumn{15}{|l|}{ Father's education ( $n$ 1256) } \\
\hline Less than 10 th grade & 237 & $18 \cdot 9$ & 25 & 29 & 32 & $<0.001$ & 11 & 13 & 14 & $<0.001$ & 14 & 16 & 18 & $<0.001$ \\
\hline 10th grade & 418 & $33 \cdot 3$ & 28 & 31 & 34 & & 12 & 13 & 14 & & 14 & 17 & 19 & \\
\hline $\begin{array}{l}\text { 13th grade (Arbitur) and higher } \\
\text { (university) }\end{array}$ & 601 & $47 \cdot 9$ & 29 & 33 & 36 & & 13 & 14 & 15 & & 16 & 19 & 21 & \\
\hline \multicolumn{15}{|l|}{ Family situation ( $n$ 1519) } \\
\hline With one parent & 537 & $35 \cdot 1$ & 27 & 31 & 35 & $0 \cdot 360$ & 11 & 13 & 14 & $<0.001$ & 14 & 17 & 19 & 0.004 \\
\hline With both parents & 995 & 64.9 & 28 & 31 & 35 & & 12 & 14 & 15 & & 15 & 17 & 20 & \\
\hline \multicolumn{15}{|l|}{ BMI of mother $\left(\mathrm{kg} / \mathrm{m}^{2} ; n 1250\right)$} \\
\hline Underweight & 35 & $2 \cdot 8$ & 28 & 33 & 39 & $<0.001$ & 12 & 14 & 15 & 0.019 & 15 & 19 & 21 & 0.002 \\
\hline Normal & 826 & $66 \cdot 1$ & 28 & 32 & 35 & & 12 & 14 & 15 & & 15 & 18 & 20 & \\
\hline Overweight & 389 & $31 \cdot 1$ & 26 & 30 & 34 & & 12 & 13 & 15 & & 14 & 17 & 19 & \\
\hline \multicolumn{15}{|l|}{ BMI of father $\left(\mathrm{kg} / \mathrm{m}^{2} ; n\right.$ 1106) } \\
\hline Underweight & 5 & 0.5 & 28 & 32 & 36 & $0 \cdot 194$ & 12 & 14 & 15 & $0 \cdot 144$ & 16 & 17 & 20 & 0.016 \\
\hline Normal & 455 & $41 \cdot 1$ & 28 & 32 & 36 & & 12 & 14 & 15 & & 15 & 18 & 21 & \\
\hline Overweight & 646 & $58 \cdot 4$ & 28 & 31 & 35 & & 12 & 14 & 15 & & 15 & 17 & 20 & \\
\hline \multicolumn{15}{|l|}{ Girls' weight status ( $n$ 1519) } \\
\hline Underweight & 113 & $7 \cdot 4$ & 26 & 31 & 35 & 0.013 & 12 & 14 & 15 & 0.030 & 13 & 16 & 19 & 0.025 \\
\hline Normal & 1232 & $80 \cdot 5$ & 27 & 31 & 35 & & 12 & 13 & 15 & & 15 & 17 & 20 & \\
\hline Overweight & 186 & $12 \cdot 1$ & 29 & 32 & 36 & & 12 & 13 & 14 & & 15 & 18 & 20 & \\
\hline
\end{tabular}

25th, 25th percentile; 75th, 75th percentile; SES, socio-economic status.

school-leaving certificate (none or Hauptschulabschluss). Over one-third had a tenth grade school-leaving certificate (Mittlere Reife) and $>45 \%$ of the mothers and fathers held a university entrance diploma (Abitur or Hochschulreife) or a college or university degree (Fach or Hochschulabschluss). With regard to family situation, $35 \cdot 1 \%$ lived in single-parent households. The parental weight status indicates that just under one-third of mothers were overweight or obese; the proportion of fathers who were overweight or obese was considerably higher $(58.4 \%)$. Of the girls, $12 \cdot 1 \%$ were overweight or obese and $7 \cdot 4 \%$ were underweight.

The association between the median food frequency score, meal context score and portion size score and selected social and weight status indicators among adolescent girls is presented in Table 2 . Statistically significant differences in food frequency scores were found according to age group, migration background, SES of parents, mothers' and fathers' education, mothers' BMI and girls' weight status. Family situation and fathers' BMI did not influence the food frequency score.

Age, migration background, SES of parents, mothers' and fathers' education, family situation and weight status of mothers and daughters were significantly related to differences in meal context scores, whereas fathers' BMI was not significant. Migration background, SES of parents, mothers' and fathers' education and BMI and daughters' weight status were significant determinants of portion size scores.

The multivariate results are organized by food frequency, meal context and portion size scores, each of which is calculated separately (Tables 3 and 4). In model 1 (Table 3), influencing factors regarding 'unfavourable food frequency scores' were: low SES $(\mathrm{OR}=3 \cdot 6)$, middle SES $(\mathrm{OR}=1 \cdot 9)$, two-parent migration background $(\mathrm{OR}=2 \cdot 3)$ and age $(\mathrm{OR}=1 \cdot 3)$. Overweight or obese status of the girls had a slightly protective influence $(\mathrm{OR}=0 \cdot 3)$ on the girls' food frequency score. Mothers' and fathers' BMI, family situation and being underweight 
Table 3 Model 1: SES as risk factor among selected indicators for unfavourable eating behaviour (multivariate logistic regression)

\begin{tabular}{|c|c|c|c|c|c|c|c|c|c|}
\hline \multirow[b]{2}{*}{ Independent variable (reference) } & \multicolumn{3}{|c|}{$\begin{array}{l}\text { Unfavourable food frequency } \\
\qquad(n 941)\end{array}$} & \multicolumn{3}{|c|}{$\begin{array}{l}\text { Unfavourable meal context } \\
\qquad(n \text { 1020) }\end{array}$} & \multicolumn{3}{|c|}{$\begin{array}{l}\text { Unfavourable portion size } \\
\qquad(n \text { 1020) }\end{array}$} \\
\hline & OR & $95 \% \mathrm{Cl}$ & $P$ & OR & $95 \% \mathrm{Cl}$ & $P$ & OR & $95 \% \mathrm{Cl}$ & $P$ \\
\hline $\begin{array}{l}\text { Age (years) } \\
\text { Migration background (no) }\end{array}$ & $1 \cdot 3$ & $1 \cdot 0,1 \cdot 9$ & $0 \cdot 019$ & $1 \cdot 5$ & $1 \cdot 2,1 \cdot 8$ & $<0.001$ & $1 \cdot 2$ & $1 \cdot 0,1 \cdot 3$ & $0 \cdot 136$ \\
\hline $\begin{array}{l}\text { One parent } \\
\text { Two parents }\end{array}$ & $\begin{array}{l}1 \cdot 4 \\
2 \cdot 3\end{array}$ & $\begin{array}{l}0 \cdot 8,2 \cdot 6 \\
1 \cdot 5,3 \cdot 6\end{array}$ & $\begin{array}{r}0.262 \\
<0.001\end{array}$ & $\begin{array}{l}1 \cdot 2 \\
1 \cdot 6\end{array}$ & $\begin{array}{l}0 \cdot 7,2 \cdot 1 \\
1 \cdot 1,2 \cdot 5\end{array}$ & $\begin{array}{l}0.463 \\
0.024\end{array}$ & $\begin{array}{l}0.5 \\
1.6\end{array}$ & $\begin{array}{l}0 \cdot 3,0 \cdot 9 \\
1 \cdot 1,2 \cdot 4\end{array}$ & $\begin{array}{l}0.001 \\
0.002\end{array}$ \\
\hline Social status (high) & & & & & & & & & \\
\hline $\begin{array}{l}\text { Middle } \\
\text { Low }\end{array}$ & $\begin{array}{l}1 \cdot 9 \\
3 \cdot 6\end{array}$ & $\begin{array}{l}1 \cdot 2,3 \cdot 0 \\
2 \cdot 1,6 \cdot 0\end{array}$ & $\begin{array}{r}0.009 \\
<0.001\end{array}$ & $\begin{array}{l}2 \cdot 1 \\
2 \cdot 3\end{array}$ & $\begin{array}{l}1 \cdot 4,3 \cdot 2 \\
1 \cdot 4,3 \cdot 8\end{array}$ & $\begin{array}{l}0.001 \\
0.001\end{array}$ & $\begin{array}{l}1 \cdot 9 \\
2 \cdot 0\end{array}$ & $\begin{array}{l}1 \cdot 3,2 \cdot 7 \\
1 \cdot 3,3 \cdot 2\end{array}$ & $\begin{array}{l}0.033 \\
0.013\end{array}$ \\
\hline Family (two adults) & & & & & & & & & \\
\hline $\begin{array}{l}\text { One parent } \\
\text { Mother (normal) }\end{array}$ & $1 \cdot 2$ & $0 \cdot 7,1 \cdot 8$ & 0.569 & $0 \cdot 6$ & $0.4,0.9$ & $0 \cdot 008$ & $0 \cdot 7$ & $0 \cdot 5,1 \cdot 1$ & 0.099 \\
\hline $\begin{array}{l}\text { Overweight } \\
\text { Underweight }\end{array}$ & $\begin{array}{l}1 \cdot 3 \\
0 \cdot 6\end{array}$ & $\begin{array}{l}0 \cdot 9,2 \cdot 0 \\
0 \cdot 1,2 \cdot 7\end{array}$ & $\begin{array}{l}0 \cdot 151 \\
0.517\end{array}$ & $\begin{array}{l}1 \cdot 1 \\
0 \cdot 5\end{array}$ & $\begin{array}{l}0 \cdot 8,1 \cdot 6 \\
0 \cdot 1,2 \cdot 4\end{array}$ & $\begin{array}{l}0.530 \\
0.409\end{array}$ & $\begin{array}{l}1 \cdot 5 \\
0 \cdot 9\end{array}$ & $\begin{array}{l}1 \cdot 1,2 \cdot 1 \\
0 \cdot 3,2 \cdot 7\end{array}$ & $\begin{array}{l}0.019 \\
0.816\end{array}$ \\
\hline Father (normal) & & & & & & & & & \\
\hline Overweight & $1 \cdot 2$ & $0 \cdot 8,1 \cdot 7$ & 0.476 & 0.9 & $0 \cdot 6,1 \cdot 3$ & 0.675 & $1 \cdot 0$ & $0.8,1.5$ & 0.792 \\
\hline $\begin{array}{l}\text { Underweight } \\
\text { Girls' BMI }\left(\mathrm{kg} / \mathrm{m}^{2} \text {; normal) }\right.\end{array}$ & - & - & - & $1 \cdot 1$ & $0 \cdot 1,11 \cdot 0$ & $0 \cdot 913$ & $0 \cdot 7$ & $0 \cdot 1,6 \cdot 4$ & $0 \cdot 735$ \\
\hline $\begin{array}{l}\text { Overweight } \\
\text { Ond }\end{array}$ & $0 \cdot 3$ & $0 \cdot 2,0 \cdot 7$ & 0.002 & $1 \cdot 1$ & $0 \cdot 6,1 \cdot 8$ & $0 \cdot 817$ & $0 \cdot 7$ & $0 \cdot 4,1 \cdot 2$ & $0 \cdot 242$ \\
\hline Underweight & $1 \cdot 6$ & $0 \cdot 8,3 \cdot 2$ & $0 \cdot 141$ & 0.6 & $0 \cdot 3,1 \cdot 3$ & $0 \cdot 217$ & $1 \cdot 6$ & $0 \cdot 9,2 \cdot 8$ & 0.094 \\
\hline
\end{tabular}

SES, socio-economic status.

Table 4 Model 2: Mothers' and fathers' education as risk factors among selected indicators for unfavourable eating behaviour (multivariate logistic regression)

\begin{tabular}{|c|c|c|c|c|c|c|c|c|c|}
\hline \multirow[b]{2}{*}{ Independent variable (reference) } & \multicolumn{3}{|c|}{$\begin{array}{l}\text { Unfavourable food frequency } \\
\qquad(n \text { 924) }\end{array}$} & \multicolumn{3}{|c|}{$\begin{array}{l}\text { Unfavourable meal context } \\
\qquad(n 998)\end{array}$} & \multicolumn{3}{|c|}{$\begin{array}{l}\text { Unfavourable portion size } \\
\text { ( }(n \text { 998) }\end{array}$} \\
\hline & OR & $95 \% \mathrm{Cl}$ & $P$ & OR & $95 \% \mathrm{Cl}$ & $P$ & OR & $95 \% \mathrm{Cl}$ & $P$ \\
\hline $\begin{array}{l}\text { Age (years) } \\
\text { Migration background (no) }\end{array}$ & $1 \cdot 2$ & $1 \cdot 0,1 \cdot 5$ & 0.057 & $1 \cdot 5$ & $1 \cdot 2,1 \cdot 8$ & $<0.001$ & $1 \cdot 2$ & $1 \cdot 0,1 \cdot 4$ & 0.087 \\
\hline One parent & $1 \cdot 4$ & $0 \cdot 8,2 \cdot 7$ & $0 \cdot 238$ & $1 \cdot 0$ & $0.6,1 \cdot 9$ & 0.894 & 0.5 & $0 \cdot 3,1 \cdot 0$ & 0.066 \\
\hline Two parents & $2 \cdot 5$ & $1 \cdot 6,3 \cdot 0$ & $<0.001$ & $1 \cdot 6$ & $1 \cdot 1,2 \cdot 6$ & 0.026 & $1 \cdot 8$ & $1 \cdot 2,2 \cdot 6$ & 0.005 \\
\hline \multicolumn{10}{|c|}{ Mothers' education (up to tenth grade) } \\
\hline Less than tenth grade & $3 \cdot 3$ & $1 \cdot 7,6 \cdot 2$ & $<0.001$ & $1 \cdot 4$ & $0 \cdot 7,2 \cdot 6$ & $0 \cdot 312$ & $1 \cdot 6$ & $0.9,2.9$ & 0.084 \\
\hline Tenth grade & 1.9 & $1 \cdot 2,3 \cdot 2$ & 0.010 & 1.9 & $1 \cdot 2,2 \cdot 9$ & 0.009 & $1 \cdot 5$ & $1 \cdot 0,2 \cdot 3$ & 0.046 \\
\hline \multicolumn{10}{|c|}{ Fathers' education (up to tenth grade) } \\
\hline Less than tenth grade & $1 \cdot 1$ & $0 \cdot 6,2 \cdot 0$ & 0.703 & $1 \cdot 6$ & $0 \cdot 9,2 \cdot 9$ & $0 \cdot 101$ & $1 \cdot 2$ & $0 \cdot 7,2 \cdot 0$ & 0.515 \\
\hline Tenth grade & $1 \cdot 1$ & $0 \cdot 7,1 \cdot 7$ & $0 \cdot 820$ & $1 \cdot 6$ & $1 \cdot 0,2 \cdot 5$ & 0.057 & $1 \cdot 4$ & $0 \cdot 9,2 \cdot 2$ & 0.085 \\
\hline \multicolumn{10}{|l|}{ Family (two adults) } \\
\hline One parent & $1 \cdot 1$ & $0 \cdot 7,1 \cdot 7$ & $0 \cdot 781$ & $0 \cdot 6$ & $0.4,0.9$ & 0.015 & $0 \cdot 8$ & $0 \cdot 6,1 \cdot 2$ & $0 \cdot 280$ \\
\hline \multicolumn{10}{|l|}{ Mother (normal) } \\
\hline Overweight & $1 \cdot 4$ & $0 \cdot 9,2 \cdot 0$ & $0 \cdot 117$ & $1 \cdot 1$ & $0 \cdot 8,1 \cdot 6$ & 0.633 & $1 \cdot 4$ & $1 \cdot 0,2 \cdot 0$ & 0.039 \\
\hline Underweight & $0 \cdot 7$ & $0 \cdot 2,3 \cdot 1$ & 0.631 & $0 \cdot 6$ & $0 \cdot 1,2 \cdot 6$ & 0.475 & 0.9 & $0 \cdot 3,2 \cdot 8$ & 0.896 \\
\hline \multicolumn{10}{|l|}{ Father (normal) } \\
\hline Overweight & $1 \cdot 3$ & $0 \cdot 8,1 \cdot 7$ & $0 \cdot 261$ & 0.9 & $0 \cdot 6,1 \cdot 3$ & 0.611 & $1 \cdot 0$ & $0 \cdot 7,1 \cdot 5$ & $0 \cdot 825$ \\
\hline Underweight & - & - & - & $1 \cdot 2$ & $0 \cdot 1,11 \cdot 3$ & 0.900 & 0.7 & $0 \cdot 1,6 \cdot 8$ & 0.772 \\
\hline \multicolumn{10}{|l|}{ Girls' BMI (normal; kg/m²) } \\
\hline Overweight & $0 \cdot 3$ & $0 \cdot 2,0.6$ & $<0.001$ & $1 \cdot 1$ & $0 \cdot 7,1 \cdot 9$ & 0.640 & 0.8 & $0 \cdot 5,1 \cdot 3$ & 0.335 \\
\hline Underweight & $1 \cdot 8$ & $0.9,3.4$ & 0.082 & 0.6 & $0 \cdot 3,1 \cdot 4$ & 0.241 & $1 \cdot 8$ & $1 \cdot 1,3 \cdot 2$ & 0.031 \\
\hline
\end{tabular}

were not statistically significant influencing factors on the girls' food frequency score. Statistically significant risk factors for the 'meal context score' - arranged from the highest to the lowest risk - were low SES $(\mathrm{OR}=2 \cdot 3)$, middle SES $(\mathrm{OR}=2 \cdot 1)$, two-parent migration background $(\mathrm{OR}=1 \cdot 6)$, age $(\mathrm{OR}=1 \cdot 5)$ and living with one parent $(\mathrm{OR}=0 \cdot 6)$. Mothers' and fathers' BMI and the girls' weight status did not have a statistically significant influence on the meal score. Statistically significant risk factors for the 'portion size score' were: low SES $(\mathrm{OR}=2 \cdot 0)$, middle SES $(\mathrm{OR}=1 \cdot 9)$, overweight mothers $(\mathrm{OR}=1 \cdot 5)$ and migration background, both two-parent $(\mathrm{OR}=1 \cdot 6)$ and one-parent $(\mathrm{OR}=0 \cdot 5)$. Age, family situation, mothers' and fathers' BMI and the weight status of girls did not have a statistically significant influence on the portion score of the girls.

The results for model 2 (Table 4) follow the same structure as those for model 1 . The statistically significant observations regarding the "unfavourable food frequency 
score' were: mothers with less than tenth grade schoolleaving certificate $(\mathrm{OR}=3 \cdot 3)$, mothers with tenth grade school-leaving certificate $(\mathrm{OR}=1 \cdot 9)$ and girls with twoparent migration background $(\mathrm{OR}=2 \cdot 5)$. Overweight or obese status of the girls had a protective influence $(\mathrm{OR}=0 \cdot 3)$ on the girls' food frequency score. Fathers' education, family situation, mothers' and fathers' BMI and girls being underweight did not have a statistically significant influence on the food frequency score of the girls. Statistically significant influencing factors for the 'meal score' were: mothers with a tenth grade school-leaving certificate $(\mathrm{OR}=1 \cdot 9)$, two-parent migration background $(\mathrm{OR}=1 \cdot 6)$, living with one parent $(\mathrm{OR}=0 \cdot 6)$ and age $(\mathrm{OR}=1 \cdot 5)$. Mothers having less than tenth grade schoolleaving certificate, fathers' education and mothers', fathers' and girls' BMI did not have a statistically significant influence on the meal score of the girls. Girls being underweight $(\mathrm{OR}=1 \cdot 8)$, two-parent migration background $(\mathrm{OR}=1 \cdot 8)$, mothers having tenth grade school-leaving certificate $(\mathrm{OR}=1.5)$ and mothers being overweight $(\mathrm{OR}=1.4)$ were risk factors for 'unfavourable portion score'. Age, family situation, mothers being underweight, fathers' BMI and girls being overweight did not have a statistically significant influence on the girls' portion score.

\section{Discussion}

Eating behaviour is an interesting field of study and is widely discussed at the national political level in Germany and Europe, in the scientific community and in popular literature. In particular, adolescents' eating behaviour is gaining new attention with the rise in obesity and nutritionrelated chronic diseases. The objective of the present study was to investigate the impact of social living conditions and girls' and/or parents' weight status on food frequency, meal context and daily portion sizes among adolescent girls. Using three different measures of eating behaviour simultaneously provided an in-depth understanding of general patterns and potential risk factors.

The study population comprised adolescent girls from Berlin, of whom $9 \cdot 6 \%$ were 11 years old, $21.7 \%$ were 12 years old, $39 \cdot 0 \%$ were 13 years old and $29 \cdot 6 \%$ were 14 years old. The age distribution of the study population is fairly representative. Slight differences exist regarding migration background (BSCOC: 36.6\%; KiGGS: $\left.14 \cdot 0 \%{ }^{(25)}\right)$. This may be due to the relatively high number of immigrants in Berlin. The BSCOC SES distribution is similar to that of the Berlin Health Report, indicating that the BSCOC sample is representative for Berlin ${ }^{(21)}$. Given the different definitions of SES, a comparison with KiGGS and the HBSC study is hardly possible in this respect ${ }^{(8)}$.

The bivariate analysis examined the results of nine relationships between either social factors or weight status and food behaviour measures. Almost all were statistically significant influencing factors, except for family situation and fathers' BMI, which did not influence the food frequency score; fathers' BMI was not significant for the meal score, and age was not significant for the portion score.

Accordingly, the hypotheses that unfavourable eating behaviour is increased with (i) migration background, (ii) lower SES/education, (iii) higher age, (iv) living with one parent and (v) being overweight or obese and/or having overweight parents were confirmed by the study results (bi- and multivariate analyses) with only very few exceptions.

Migration background and SES were strongly linked with a less-favourable eating behaviour. These findings are confirmed by other studies ${ }^{(10,26)}$. Kleiser et al. ${ }^{(10)}$ conclude that the food intakes of young people with a migration background living in Germany are subject to considerable variation. Food is that component of culture that is easiest to carry along when moving to another country. With access to basic foods, almost anybody can compose a familiar meal from their home country, which means that staple food components play a central role and are changed last ${ }^{(27)}$. Main dietary composition changes occur in complementary and accessory foods, which leads to an increased tendency towards consumption of non-recommended foods such as soft drinks, snacks and fast food. For example, in the present study, girls with a two-parent migration background consumed vegetables and salad more often, but they also consumed a lot more soft drinks and sweets in comparison with girls from a no-migration background. It has to be taken into account that adolescents with a migration background more often have parents with low SES and low education, which supports a less-favourable eating behaviour. SES and low education are independently associated with food intake ${ }^{(28)}$. In the present study, the greatest social gradient was found in the food frequency score. Throughout history and in different demographic groups, SES has been consistently associated with health ${ }^{(29)}$. Other studies have also found that lower SES groups consume unhealthier foods more frequently despite different definitions ${ }^{(11,30-32)}$. On the contrary, consumption of fruit and vegetables is higher in higher SES groups ${ }^{(5,8,29)}$. Our study showed a higher percentage of the low SES group having fewer regular meals, similar to the study by Hoglund et $a l^{(33)}$. Owing to the nature of the cumulative outcome variables in the present study, it could not be established whether the number of daily meals or the meal context (with parents or on the way) influences the outcome of eating behaviour. However, this measure is factored into the score and thus may contribute to the findings that the low SES group has less-favourable meal context eating behaviour. 'Parental education' showed gender differences. Although mothers' educational level was a risk factor for all components of eating behaviour, fathers' educational level did not play a role at all. This is in agreement with the argument of Winkleby et $a l^{(34)}$, who stated that, specifically, mothers' education is the strongest predictor of health within the SES. Education 
represents more than formal schooling and nutritional knowledge; rather, it includes lifestyles, attitudes and approaches. Mothers' education may be more important than fathers' education for adolescent girls' eating behaviour because mothers usually prepare meals, spend more time with the children and act as role models, especially for girls ${ }^{(35)}$. Elfhag and Linne ${ }^{(36)}$ determine that eating pathology is shared by mothers and daughters, but not by sons. The employment status of parents had no influence on eating behaviour, as described by Würbach et al. ${ }^{(37)}$.

Surprisingly, and contrary to the findings of other studies, we found a positive association only between age and unfavourable meal scores. Several other studies found an increase in unhealthy food consumption frequency, e.g. sweets, fast food ${ }^{(4,11)}$ and soft drinks ${ }^{(5,38)}$, and a decrease in the consumption of healthy food such as fruit and vegetables (S Bartsch, unpublished results) in older children. No cumulative meal scores are found in the literature; however, individual aspects of meal contexts support the findings of the present study. The frequency of eating breakfast with parents decreases with older age ${ }^{(8,38)}$. With the transition from childhood to adulthood, adolescents seek to claim their independence and eat less frequently with the family ${ }^{(30)}$ or at home and may skip meals altogether. These are possible reasons why adolescents exhibit lower meal scores as they get older. The reasons why, in the BSCOC study, meal scores are associated with age, whereas the food frequency and portion scores are not, remain open to debate.

'Family situation' was associated with unfavourable meal scores, but not with food frequency or portion scores. The family still remains the dominant setting for meal consumption (S Bartsch, unpublished results). The National Longitudinal Study of Adolescent Health found that students in one-parent households have a higher risk of unfavourable eating behaviour 'such as skipping breakfast and lunch, eating fewer vegetables, [and] consuming more fast food ${ }^{\text {(39). }}$. In further analyses, details of this interaction with the other measures of eating behaviour on one side and social factors on the other should be focused upon.

Interestingly, weight status was less important in girls' eating behaviour. 'Overweight in parents' was relevant only for mothers. Numerous studies have shown that overweight in parents influences the child's eating behaviour $^{(2,40-45)}$. The fact becomes apparent that overweight parents influence the child's eating behaviour negatively ${ }^{(46-48)}$. Similar to parents' education, overweight mothers may have more of an influence than fathers because they spend more time with the girls and are more involved with food preparation in the household ${ }^{(35)}$.

Our findings did not support 'overweight in girls' as a risk factor for unfavourable eating behaviour. Contrary to our hypothesis, being overweight was slightly protective for the food frequency score. Our finding has to be interpreted with caution, as social desirability among other factors could play a role. This is clearly opposed to the findings that obesity is correlated with unhealthy eating ${ }^{(10,49,50)}$ and skipping breakfast ${ }^{(31,51-55)}$. With regard to the composite meal score, the findings are inconclusive ${ }^{(56,57)}$, indicating the need for further research.

\section{Benefit of using different measures of eating behaviour}

Taking the multivariate results into account, two patterns are obvious. First, there are risk factors ubiquitously relevant for eating behaviour. Our results showed a consistent significance of SES or mothers' education and migration background in relation to the three selected components of eating behaviour. Second, the relevance of other risk factors is dependent on the measure of eating behaviour. For example, having an overweight mother and being an underweight girl are associated only with unfavourable portion sizes. With regard to the risk factors, the meal context score seems to be different compared with the other two components of eating behaviour. Rather than finding categorical influences, e.g. parental education, migration background or weight status, on the eating behaviour of adolescent girls in Berlin, gender differences in parental influence are observed.

\section{Conclusion}

Gender differences emerge as a central theme from the findings of the present study. The girls' eating behaviour is less affected by categorical influences than by the gender of their parents. The disaggregate SES component of mothers' education is clearly seminal in shaping the social gradient in relation to all three components of eating behaviour. Fathers' education on the other hand is not a significant factor in the multivariate analysis. Savage et al. ${ }^{(35)}$ argue that mothers' education has such a strong influence on girls' eating behaviour because 'in most families, women still have primary responsibility for feeding children'. Campbell et al. ${ }^{(58)}$ note that especially mothers influence the home food environment, which is crucial in 'determining adolescents' (...) eating' ${ }^{(36)}$ and in establishing a link in eating behaviour between mothers and daughters, but not between the former and their sons. Interventions are needed at multiple levels. These can be successful only when preventive measures involve parents, children and adolescents. Specific interventions accounting for age, gender, migration background and the socio-economic background of the target group are necessary without stigmatizing groups that are already vulnerable ${ }^{(59,60)}$.

\section{Acknowledgements}

The present BSCOC study was funded by the EU FP 6 Network of Excellence 'Environmental and endogenous factors influencing puberty onset. Programming effects of 
early nutrition on long-term health' 2005-2008 reference no. 513991 puberty onset - influence of environmental and endogenous regulators (PIONEER). There is no conflict of interest that could be perceived as prejudicing the impartiality of the research reported. A.-M.B. and B.B. conceptualized and supervised the study and provided assistance in analysing the data, interpreting the results and writing the final manuscript; S.K., former Master's student of Health and Society International Gender Studies Berlin, conducted the initial secondary analysis under the supervision of A.-M.B. and B.B. for her Master's thesis; A.E. provided specific knowledge, contributed to interpreting the results and writing the final manuscript and was responsible for data management and analysis. All authors read and approved the final manuscript. The authors would like to express their deepest gratitude to the participating girls and their parents, teachers and schools.

\section{References}

1. World Health Organization (2009) Chronic diseases and health promotion. The causes of chronic diseases. http://www.who.int/chp/chronic_disease_report/part2_ch1/ en/index12.html (accessed September 2009).

2. Birch LL \& Davison K (2001) Family environmental factors influencing the developing behavioural controls of food intake and childhood overweight. Pediatr Clin North Am 48, 893-907.

3. Savige G, Ball K, Worsley A et al. (2007) Food intake patterns among Australian adolescents. Asia Pac J Clin Nutr 16, 738-747.

4. Mensink GBM, Kleiser C \& Richter A (2007) Food consumption of children and adolescents in Germany. Results of the German Health Interview and Examination Survey for Children and Adolescents (KiGGS). Bundesgesundheitsblatt Gesundheitsforschung Gesundheitsschutz 50, 609-623.

5. Vereecken CA, Inchley J, Subramanian SV et al. (2005) The relative influence of individual and contextual socio-economic status on consumption of fruit and soft drinks among adolescents in Europe. Eur J Public Health 15, 224-232.

6. Rasmussen M, Krølner R, Klepp KI et al. (2006) Determinants of fruit and vegetable consumption among children and adolescents: a review of the literature. Part I: quantitative studies. Int J Behav Nutr Phys Act 3, 22.

7. Alexy U, Sichert-Hellert W \& Kersting M (2002) Fifteen-year time trends in energy and macronutrient intake in German children and adolescents: results of the DONALD Study. Br J Nutr 87, 595-604.

8. Bettge S, Nickel J, Schulz M et al. (2008) Gesundheitsberichterstattung Berlin Spezialbericht Gesundheits- und Risikoverhalten von Berliner Kindern und Jugendlichen Ergebnisse der HBSC-Studie 2006. Berlin: Senatsverwaltung für Gesundheit, Umwelt und Verbraucherschutz.

9. Kleiser C, Schaffrath Rosario A, Mensink GBM et al. (2009) Potential determinants of obesity among children and adolescents in Germany: results from the cross-sectional KiGGS study. BMC Public Health 9, 46.

10. Kleiser C, Mensink G, Neuhauser H et al. (2009) Food intake of young people with a migration background living in Germany. Public Health Nutr 13, 324-330.

11. Kersting M, Alexy U, Kroke A et al. (2004) Kinderernährung in Deutschland Ergebnisse der DONALD-Studie. Bundesgesundheitsblatt Gesundheitsforschung Gesundheitsschutz 47, 213-218.
12. Plachta-Danielzik S, Kriwy P \& Müller MJ (2008) School-based intervention of the Kiel Obesity Prevention Study (KOPS). Praevention Gesundheitsfoerderung $\mathbf{3}$, 206-212.

13. Chin YS \& Mohd Nasir MT (2009) Eating behaviours among female adolescents in Kuantan District, Pahang, Malaysia. Pakistan J Nutr 8, 425-432.

14. Bau AM, Ernert A, Schenk L et al. (2009) Is there a further acceleration in the age at onset of menarche? A crosssectional study in 1840 school children focusing on age and bodyweight at the onset of menarche. Eur J Endocrinol 160, 107-113.

15. Krull S (2009) Association between selected eating behaviour indicators and social- and weight status among adolescent girls in Berlin: results of the cross-sectional BSCOC-Study. Master thesis, Health and Society: International Gender Studies Berlin, Charité - Universitätsmedizin Berlin.

16. Mast M, Körtzinger I \& Müller MJ (1999) Ernährungsverhalten und Ernährungszustand von 5-7-jährigen Kindern in Kiel. Akt Ernährungsmedizin 23, 1-6.

17. Kersting M, Zempleni G \& Schöch G (1993) 'Optimierte Mischkost' als Präventionsnahrung für Kinder und Jugendliche. Ernährungs-Umschau 40, 164-168.

18. Kersting M, Zempleni G \& Schöch G (1993) 'Optimierte Mischkost' als Präventionsnahrung für Kinder und Jugendliche - Teil 2. Ernährungs-Umschau 40, 204-209.

19. Winkler G, Schwertner B \& Döring A (1995) Kurzmethoden zur Charakterisierung des Ernährungsmusters: Einsatz und Auswertung eines Food-Frequency-Fragebogens. Ernährungs-Umschau 42, 289-291.

20. Mannhardt S (2003) Ernährungspyramide für Kinder: Entwicklung und Anwendung. Ernäbrung im Fokus 3, 206-209.

21. Oberwöhrmann S \& Bettge S (2008) Gesundheitsberichterstattung Berlin Spezialbericht Grundauswertung der Einschulungsdaten 2006 zur gesundheitlichen und sozialen Lage von Kindern in Berlin. Berlin: Senatsverwaltung für Gesundheit, Umwelt und Verbraucherschutz.

22. Schenk L, Bau AM, Borde T et al. (2007) Mindestindikatoransatz zur Erfassung des Migrationsstatus. Empfehlungen für die epidemiologische Praxis. Bundesgesundheitsblatt Gesundheitsforschung Gesundheitsschutz 49, 853-860.

23. World Health Organization (2009) Global database on body mass index. BMI classification. http://apps.who.int/bmi/ index.jsp?introPage $=$ intro_3.html (accessed September 2009).

24. Kromeyer-Hauschild K, Wabitsch M, Kunze D et al. (2001) Perzentile für den Body-Mass-Index für das Kindes-und Jugendalter unter Heranziehung verschiedener deutscher Stichproben. Monatsschr Kinderheilkd 149, 807-818.

25. Kurth BM \& Schaffrath Rosario A (2007) Die Verbreitung von Übergewicht und Adipositas bei Kindern und Jugendlichen in Deutschland. Ergebnisse des Kinder und Jugendgesundheitssurvey (KiGGS). Bundesgesundheitsblatt Gesundheitsforschung Gesundheitsschutz $\mathbf{5 0 ,}$ 736-743.

26. Bau AM, Matteucci Gothe R \& Borde T (2003) Ernährungsverhalten von 3- bis 6-jährigen Kindern verschiedener Ethnien - Ergebnisse einer Kitastudie in Berlin. ErnäbrungsUmschau 50, 214-218.

27. Koctürk T (1996) Structure and change in food habits. Scand J Nutr 40, 108-110.

28. Rüter J (2010) Der Einfluss des Migrationshintergrundes auf das Ernährungsverhalten 11-14-jähriger Mädchen in Berlin - Ergebnisse der BSCOC-Studie, Diplomarabeit, Fachbereich Ernährungswissenschaft der MathematischNaturwissenschaftlichen Fakultät der Universität Potsdam.

29. Lynch J \& Kaplan G (2000) Socioeconomic position. In Social Epidemiology, pp. 13-35 [LF Berkman and I Kawachi, editors]. New York: Oxford University Press. 
30. Mitchell JE, Resnick MD, Blum RW et al. (1997) The relationship between socioeconomic status and eatingdisordered behaviours in a community sample of adolescent girls. Int J Eat Disord 22, 15-23.

31. Merten MJ, Williams AL \& Shriver LH (2009) Breakfast consumption in adolescence and young adulthood: parental presence, community context, and obesity. J Am Diet Assoc 109, 1384-1391.

32. Ravens-Sieberer U \& Thomas C (2003) Gesundheitsverhalten von Schülern in Berlin, Ergebnisse der HBSCJugendgesundheitsstudie 2002 im Auftrag der WHO. Berlin: Robert Koch Institut.

33. Hoglund D, Samuelson G \& Mark A (1998) Food habits in Swedish adolescents in relation to socioeconomic conditions. Eur J Clin Nutr 52, 784-789.

34. Winkleby MA, Jatulis DE, Frank E et al. (1992) Socioeconomic status and health: how education, income, and occupation contribute to risk factors for cardiovascular disease. Am J Public Health 8, 816-820.

35. Savage JS, Fisher JO \& Birch LL (2007) Parental influence on eating behaviour: conception to adolescence. J Law Med Ethics 35, 22-34.

36. Elfhag K \& Linne Y (2005) Gender differences in associations of eating pathology between mothers and their adolescent offspring. Obes Res 13, 1070-1076.

37. Würbach A, Zellner K \& Kromyer-Hauschild K (2009) Meal pattern among children and adolescents and their associations with weight status and parental characteristics. Public Health Nutr 12, 1115-1121.

38. Story M \& Stang J (editors) (2005) Understanding adolescent eating behavior. In Guidelines for Adolescent Nutrition Services, pp. 9-19. http://www.epi.umn.edu/let/ pubs/img/adol_ch2.pdf (accessed August 2009).

39. Neumark-Sztainer D, Story M, Hannan PJ et al. (2002) Overweight status and eating patterns among adolescents: where do youths stand in comparison with the Healthy People 2010 objectives? Am J Public Health 92, 844-851.

40. Mitchell MK (2003) Nutrition Across the Life Span, 2nd ed. Philadelphia, PA: Saunders.

41. Stewart SD \& Menning CL (2009) Family structure, nonresident father involvement, and adolescent eating patterns. J Adolesc Health 45, 193-201.

42. Cullen KW, Lara KM \& de Moor C (2002) Familial concordance of dietary fat practices and intake. Fam Community Health 25, 65-75.

43. Davison KK \& Birch LL (2001) Child and parent characteristics as predictors of change in girls' body mass index. Int J Obes Relat Metab Disord 25, 1834-1842.

44. Davison KK \& Birch LL (2002) Obesigenic families: parents' physical activity and dietary intake patterns predict girls' risk of overweight. Int J Obes Relat Metab Disord 26, 1186-1193.

45. Wardle J, Guthrie C, Sanderson S et al. (2001) Food and activity preferences in children of lean and obese parents. Int J Obes Relat Metab Disord 25, 971-977.
46. Francis LA, Ventura AK, Marini M et al. (2007) Parent overweight predicts daughters' increase in BMI and disinhibited overeating from 5 to 13 years. Obesity (Silver Spring) 15, 1544-1553.

47. Fisher JO, Mitchel DC, Smiciklas-Wright H et al. (2002) Parental influences on young girls' fruit and vegetable, micronutrient, and fat intakes. J Am Diet Assoc 102, 58-64.

48. Hanson NI, Neumark-Sztainer D, Eisenberg ME et al. (2004) Associations between parental report of the home food environment and adolescent intakes of fruits, vegetables and dairy foods. Public Health Nutr 8, 77-85.

49. Nicklas TA, Yang S, Baranowski T et al. (2003) Eating patterns and obesity in children. Am J Prev Med 24, 9-16.

50. Niemeier HM, Raynor HA, Lloyd-Richardson EE et al. (2006) Fast food consumption and breakfast skipping: predictors of weight gain from adolescence to adulthood in a nationally representative sample. J Adolesc Health 39, 42-49.

51. Sjöberg A, Hallberg L, Höglund D et al. (2003) Meal pattern, food choice, nutrient intake and lifestyle factors in the Göteborg Adolescence Study. Eur J Clin Nutr 57, 1569-1578.

52. Stockman NK, Schenkel TC, Brown JN et al. (2005) Comparison of energy and nutrient intakes among meals and snacks of adolescent males. Prev Med 41, 203-210.

53. Berkey CS, Rockett HR, Gillman MW et al. (2003) Longitudinal study of skipping breakfast and weight change in adolescents. Int J Obes Relat Metab Disord 27, 1258-1266.

54. Berteus-Forslund H, Lindroos AK, Syjöström L et al. (2002) Meal patterns and obesity in Swedish women - a simple instrument describing usual meal types, frequency and temporal distribution (abstract). Eur J Clin Nutr 56, $740-747$.

55. Ortega RM, Redondo MR, López-Sobaler AM et al. (1996) Associations between obesity, breakfast-time food habits and intake of energy and nutrients in a group of elderly Madrid residents. J Am Coll Nutr 15, 65-72.

56. Livingstone MB (2000) Epidemiology of childhood obesity in Europe. Eur J Pediatr 159, S14-S34.

57. Goldapp C \& Mann R (2004) Zur Datenlage von Übergewicht und Adipositas bei Kindern und Jugendlichen. Sonderdruck Prävention 27, 12-18.

58. Campbell KJ, Crawford DA, Salmon J et al. (2007) Associations between the home food environment and obesity-promoting eating behaviours in adolescence. Obesity (Silver Spring) 15, 719-730.

59. Kolip P (2004) Der Einfluss von Geschlecht und sozialer Lage auf Ernährung und Übergewicht im Kindesalter. Bundesgesundheitsblatt Gesundheitsforschung Gesundbeitsschutz 47, 235-239.

60. Flynn MAT, McNeil DA, Maloff B et al. (2006) Reducing obesity and related chronic disease risk in children and youth: a synthesis of evidence with 'best practice' recommendations. Obes Rev 7, 7-66. 